\title{
8 As famílias com doentes mentais
}

\author{
【Maria Filomena Pereira Gomes'; Maria Manuela Martins²; José Amendoeira ${ }^{3}$
}

\section{RESUMO}

As políticas de saúde vão no sentido de se manterem os doentes mentais na comunidade. À família é exigido o papel de cuidador para o qual não está preparada, não compreende o comportamento do doente nem as manifestações da doença lidando ainda com a culpa, a sobrecarga física e emocional, o isolamento social, e, muitas vezes, dificuldades económicas.

Com este estudo pretendemos identificar necessidades em saúde nas famílias com doentes mentais e desenvolver estratégias saudáveis para ultrapassar as dificuldades causadas pela doença. Queremos assim contribuir para a promoção da saúde das famílias com doentes mentais.

Optamos por uma amostra constituída por 20 famílias de doentes mentais. Recorremos a entrevistas semi-estruturadas. O tratamento de dados foi sujeito a análise de conteúdo

As famílias sentem-se inseguras e sem saber o que fazer, manifestando que seria importante saber como lidar com o doente e a quem recorrer numa situação de desequilíbrio. Estas informações são importantes no planeamento de cuidados e permitem aos enfermeiros que trabalham com família de doentes mentais intervir junto delas ajudando-as a reajustarem-se aos seus novos projectos de vida.

\section{PALAVRAS-CHAVE: Doentes Mentais; Cuidados;} Famílias.

\section{ABSTRACT}

Health policies support that people with mental disease should live within the community. Families are expected to take care of their mentally ill members but they are not prepared to deal with it. The family does not understand the patient's behavior or the manifestations of the disease still dealing with guilt, physical and emotional burden, social isolation, and often economic difficulties.

The aim of this study is to identify the health needs in families with mentally ill and develop healthy strategies to overcome the difficulties caused by the disease. We want to help to promote the health of families with mentally ill patients.

A sample of 20 families of mentally ill was studied through semi-structured interviews. Data processing was subjected to content analysis.

Families feel insecure, not knowing what to do. They state that it would be important to know how to deal with the patient and who can help them when they turn to an imbalance. This information is important to plan some care and enable nurses working with families of mental patients to intervene with them, so that they can readjust to their new life projects.

\section{KEYWORDS: People with Mental IIIness; Health Care; Families.}

\section{INTRODUÇÃO}

As orientações políticas sobre a saúde, e, particularmente sobre a saúde mental vão no sentido de se manterem os doentes mentais na comunidade. Aí, as observações relativas à responsabilidade da família sobre o adoecer de um dos seus membros são frequentes. Em muitas situações e, aparentemente cada vez mais, a família, ou a ausência dela, constitui o centro de perturbações emocionais.

Alguns comportamentos, mais ou menos agressivos, que, por vezes, se verificam nas famílias têm uma dimensão diferente das observadas noutros contextos. Por outro lado, esperase que seja aqui que qualquer elemento do grupo familiar encontre suporte psíquico e emocional para responder às complexas exigências da sociedade actual.

A família é reconhecida como o grupo social mais significativo da sociedade e tem sofrido alterações ao longo dos tempos, tanto na sua estrutura como no desempenho dos seus papéis e nas interacções com a comunidade. A família constitui o primeiro lugar de toda e qualquer educação e, assegura a ligação entre o afectivo e cognitivo e a transmissão de valores (Unesco: 1996).

\footnotetext{
${ }^{1}$ Doutoranda e Professora Coordenadora na Escola Superior de Enfermagem da Universidade do Minho, fgomes@ese.uminho.pt

${ }^{2}$ Doutora e Professora Coordenadora na Escola Superior de Enfermagem do Porto, mmartins@senf.pt

${ }^{3}$ Doutor e Professor Coordenador na Escola Superior de Enfermagem de Santarém, jjpam @netcabo.pt

Submetido em 22-01-2011. Aceite em 31-05-2011.

Citação: Gomes, M. F. P.; Martins, M. M. \& Amendoeira, J. (2011). As famílias com doentes mentais. Revista Portuguesa de Enfermagem de Saúde Mental, 5, 52-58.
} 
Apesar de sabermos que os jovens de hoje adquirem a sua identidade também fora da família, esta não pode deixar de se responsabilizar pelo crescimento dos seus membros. É nela que cada um encontra o espaço educativo por excelência, e é frequentemente considerada onúcleo central de individualização e socialização essencialmente devido à multiplicidade de estímulos para o desenvolvimento de emoções e afectos, positivos e negativos, entre todos os elementos que são essenciais para um crescimento saudável. Estas interacções interferem com o desenvolvimento dos seus membros no interior da família sendo, também, este o espaço onde se adquire o conceito de saúde e hábitos de vida saudável.

Quando em presença de doença mental a familia enfrenta situações mais complexas do que aquelas que viveria se esta condição não existisse, talvez por não ter conhecimento sobre a doença, por não compreender a sintomatologia ou porque as perspectivas de vida, tanto do doente como dos outros membros da familia poderão ser afectadas. Mesmo quando se adaptam com a presença da doença fazem-no à custa de muitas privações. Reduzem a sua participação em eventos, mudam hábitos sociais e no relacionamento familiar, intensificam a atenção sobre o doente e convivem com o estigma e mitos que ainda hoje persistem (Nasi, Stumm, Hildebrandt, 2004). Estas autoras acrescentam que a equipe de saúde, frequentemente, só se preocupa com o doente e com sua medicação. Reforçam ao familiar que a única alternativa é o uso correto da medicação e muitas vezes esquecem-se de se aproximar desta família que também precisa de atenção e de acompanhamento adequado.

Ao analisarmos muitos dos estudos publicados sobre as familias que convivem com doentes mentais encontramos concordancia sobre o sofrimento de todo o agregado. Por outro lado, não é fácil encontrar estudos que tenham a familia como actores centrais no sentido de os ajudar a adequar estratégias com as quais eles próprios se sintam bem, isto é, que procurem o bem estar de todos e cada um individualmente.

Outros estudos têm demonstrado que as famílias muitas vezes não sabem como resolver os seus problemas por desconhecerem a doença mental e sistemas de apoio comunitário a que possam recorrer (Amaral e Durman, 2004; Colvero, Ide e Rolim, 2004). Perante estas dificuldades as relações e as possibilidades de convivência entre os doentes e os seus familiares são prejudicadas. Esta coabitação com o doente e com a doença deve permitir à família "ser tratada como um cliente que necessita de cuidado, porque apresenta problemas específicos" (Oliveira e Loyola, 2004: 221). Por isso defendemos que o centro da intervenção deve ser a família para que possa realmente expressar as suas reais dificuldades para, então, poder usufruir de uma melhor qualidade de vida. Este conceito já foi expresso pelo Comité Económico e Social Europeu (2006: 11) ao defender que se deve criar uma estratégia para resolver os problemas de saúde mental mas terá que ser apoiada na sociedade do conhecimento para que haja "uma ideia clara dos conceitos relacionados com a saúde mental e do que abrangem" mas também que tenha capacidade para captar a amplitude do problema e a dinâmica que ele comporta.

A Comissão responsável pela elaboração do Plano Nacional de Saúde Mental 2008-2016 reconhece que há problemas que contribuem para $o$ reduzido progresso na área da psiquiatria, nomeadamente "i) $A$ reduzida participação de utentes e familiares; ii) A escassa produção científica no sector da psiquiatria e saúde mental; iii) A limitada resposta às necessidades de grupos vulneráveis; e iv) $A$ quase total ausência de programas de promoção/prevenção" (PNSM, 2008, p.59). Paralelamente o Ministério da Saúde, pela voz da Alta Comissária para a Saúde, expressa que o Ministério da Saúde "está empenhado em executar as recomendações da OMS-Euro, de forma a obter mais ganhos em saúde para a população portuguesa, a assegurar a sustentabilidade do sistema de saúde e a reduzir desigualdades em saúde", Março último após o conhecimento da avaliação do Plano Nacional de Saúde 2004-2010 que prova que as metas em saúde mental não foram alcançadas.

\section{A FAMÍLIA DO DOENTE MENTAL: BREVE ABORDAGEM}

Uma família saudável será aquela que, em situação de ajustamento e adaptação a uma situação de stress: i) é capaz de dar resposta às necessidades dos seus membros, de lidar de forma eficaz com as transições; ii) é flexível face à distribuição do poder; e iii) mantém os padrões de interacção e as regras de funcionamento entre si e com a comunidade onde se insere (McCubbin e McCubbin, 1993). Olson e colaboradores (1989) consideram, ainda, a necessidade de manutenção de um equilíbrio de coesão e de adaptabilidade, facilitadores de uma boa comunicação entre os seus membros.

Observamos no dia-a-dia que as perturbações mentais exercem grande impacto sobre o equilíbrio das famílias, porque "essas famílias proporcionam não só apoio físico e emocional, mas suportam também o impacto negativo do estigma e da descriminalização" (OMS, 2002: 58). Quando estas famílias não conseguem utilizar as suas estratégias de adaptação, necessitam de ajuda externa, "...fontes de suporte (...) comunitário, disponíveis” (Martins: 2002: 139), que lhes permita recuperar o equilíbrio.

A literatura revela-nos que o aparecimento da doença mental num membro da família faz com que esta família precise de ajuda para lidar com "... a culpa, a sobrecarga, o pessimismo e o isolamento social, que surgem do sofrimento que a loucura imprime, tanto para eles quanto para a pessoa que adoece" (Souza e Scatena, 2005: 174).

Também referem que cada família que convive com a doença mental vive essa experiência de uma forma única e constitui 
sempre "um momento crítico do seu ciclo de desenvolvimento" (Souza e Scatena, 2005: 177).

É necessário encontrar soluções para ajudar a família a repor o seu equilíbrio emocional. Por isso, é necessário ir-se ao encontro destas pessoas para que sejam elas a expressarem o que pensam e como convivem com a situação no quotidiano.

A revisão da literatura especializada demonstra que as primeiras tentativas sistemáticas de avaliar o impacto da sobrecarga da doença mental para a família surgiram em 1955, que investiga os problemas emocionais e cognitivos apresentados pelas esposas durante a doença dos seus maridos, ao processo de ajustamento à doença na família, e à insatisfação das famílias face à informação disponível e ao acesso aos profissionais de saúde (Marsh:1992).

Schene et al. (1993) ao fazer uma revisão de 21 instrumentos mais usados, para avaliar o impacto da doença mental na família, lembram-nos que todos os pesquisadores consideram os sintomas e os comportamentos do doente como sendo factores de stress crónicos com os quais os membros da família devem aprender a lidar. As alterações da dinâmica familiar verificam-se a vários níveis, tais como: i) sentimentos de angústia; ii) consequências financeiras resultantes de desemprego ou assiduidade precária; iii) interacção familiar prejudicada; iv) afastamento rede social da família; v) estigma; vergonha; vi) pouca participação em actividades de lazer; de entre outras.

Face a tanta complexidade nas dinâmicas familiares destas famílias, é necessário ir ao seu encontro para que se possa construir um projecto terapêutico que as ajude a encontrar resposta para as suas dificuldades, incorporadas e articuladas com outros sectores sociais centradas no modelo de intervenção em promoção da saúde.

Assim, pretendemos com este estudo: identificar necessidades em saúde nas famílias com doentes mentais para que possam desenvolver estratégias saudáveis para ultrapassar as dificuldades causadas pela doença. É nosso objectivo, também, contribuir para a promoção da saúde das famílias com doentes mentais.

É esse o nosso propósito ao tentarmos identificar os seus recursos e as suas necessidades para a implementação de um modelo de promoção de saúde.

\section{METODOLOGIA}

Após o cumprimento de todos os procedimentos éticos, tanto junto das Instituições onde os doentes estavam internados e dos familiares a entrevistar, seguimos o nosso percurso de colheita de dados até à sua análise.

\section{Amostra}

O universo do nosso estudo integra familiares de doentes com diagnóstico formulado pelo psiquiatra das entidades hospitalares onde forem realizadas as entrevistas. A amostra é constituída por vinte famílias num total de trinta e cinco elementos.

\section{Instrumento de Colheita de Informação}

A escolha de um instrumento de colheita de dados esteve condicionada pela informação que pretendíamos obter. Assim, porque consideramos o Modelo Calgary de Avaliação da Família como uma estrutura multidimensional: estrutural, de desenvolvimento e funcional que permitem colher dados importante para o conhecimento da família, optamos por elaborar uma entrevista semi-estruturada baseada nestes fundamentos. Também consideramos que estas três categorias de avaliação são fundamentais e conceptualiza o exercício do enfermeiro de família. O modelo original foi apresentado por Wrigth e Leahey em 2002.

O guião da entrevista semi-estruturada foi, assim, construído a partir do Modelo de Avaliação Familiar de Calgary e é constituído por 19 questões.

\section{Procedimentos}

Procedemos à selecção aleatória das famílias, para a realização das entrevistas, que obedecessem aos critérios de inclusão atrás descritos. As famílias que entraram no estudo respeitavam os critérios pré estabelecidos. Teriam que ter um familiar internado com um diagnóstico do foro psiquiátrico formulado pelo médico da unidade de cuidados onde decorria o internamento, e, simultaneamente, aceitassem participar no estudo.

Foi utilizado um guião de entrevista semi-estruturada.

Para que pudessem decidir livremente se iriam ou não participar nas entrevistas, foram informados sobre todos os procedimentos a adoptar.

Foram respeitados todos os princípios éticos exigidos num processo de investigação tanto no que se referem aos procedimentos com as Instituições envolvidas como com os familiares.

É um estudo qualitativo. Os dados estão a ser analisados com recurso à análise de conteúdo com o auxílio do software nvivo8. Não estando esta fase do trabalho concluída, já encontramos, no entanto, alguns resultados que nos permitem tirar algumas conclusões. 


\section{ANALISE DOS RESULTADOS}

Assim, e face ao que atrás ficou expresso, temos dados que nos permitem identificar algumas dificuldades dos familiares.

Quando as famílias estão conscientes da situação de doença de um familiar, poderíamos esperar que fossem capazes de agir em conformidade e gerir as suas vidas dentro de padrões normais do grupo social onde estão inseridos, isto é, tivessem assimilado um coping capaz de agir com naturalidade no meio onde habitam. No entanto, encontramolas inseguras pela complexidade do comportamento da doença, pela pouca informação que têm sobre a evolução, como se comportarem perante as manifestações do doente e com dificuldade em gerir as suas emoções. Verificamos que um elevado número de familiares declaram não saber nada sobre a doença, inclusive, em alguns casos, atribuem a causa a "cismas", como nos relata, por exemplo, a filha de uma doente: "...isto são muitas cismas, porque ela, ela começou por achar-se gorda, começou por sentir-se feia, começou a engolir tudo para dentro dela e nunca falava com ninguém (...) depois daí cresceu um monstro dentro da cabeça dela com muitas fantasias" (F5e1). Noutros casos consideram que a situação de instabilidade social do País contribuiu para o agravamento da doença "... como ficou doente e se fala numa crise tão grande ele começou a pôr na cabeça dele que ia passar fome" (F10c). Não duvidamos que isso tenha influência, mas uma intervenção adequada dos enfermeiros podem ajudar a compreender melhor estas razões e a aceitá-las como factores desencadeadores do desequilíbrio. Relativamente à capacidade de reorganização familiar face à doença observamos que as famílias referem ter mais dificuldade de se reorganizar face ao aspecto económico. As responsabilidades de educação são tidas em conta, normalmente com preocupação, especialmente quando está em causa o desempenho escolar como podemos confirmar pelos discursos de familiares: "... o menino que tem 12 anos, perdeu um ano de escola..." (F13d), ou: "As minhas filhas sentem muito a falta da minha esposa [voz trémula]. A mais nova é muito boa aluna, a mais velha nem tanto e como agora perde algum tempo a ajudar-me com as tarefas lá de casa, estuda menos e tenho medo que as notas baixem..." (F20c). É evidente a reorganização face aos papéis dos membros da família, mas com prejuízo para algum deles, neste caso a educação formal.

Manifestam dificuldade em lidar com a incerteza dos comportamentos do elemento doente "...nunca se está sossegada, nunca se sabe se a refeição vai ser sossegada, se não vai. (...) é sempre uma incerteza" (F11a), ou: "É a incerteza do futuro, é a incerteza. Quando ele sair daqui é ... Porque a gente é constantemente enganada. (...) a gente tá sempre a jogar na defesa, sempre a ver o que vai acontecer e sabe (...) isto cria uma angustia dentro de nós" (F11g). Estas dificuldades de convivência tornam-se muito mais claras quando o desejo, muitas vezes oculto, é verbalizado: "se houvesse uma casa onde estes doentes pudessem ficar... (...)
Se houvesse possibilidade de ficar aqui, (...) seria melhor ele ficar aqui!" (F3c).

Quem pode intervir directamente junto destas famílias no sentido de as ajudar ou de encaminhar para a obtenção de apoios para minorar o seu sofrimento, muitas vezes manifestado por sentimentos de angustia, são os enfermeiros. No entanto, quando pedimos aos familiares de quem recebem apoio para lidar com as situações mais complexas, algumas que requerem novo internamento, os relatos são todos muito próximos "Não sei... Só se for pelo mesmo... pelo mesmo processo que foi agora. Porque ele agora veio com a guarda p'raí".(F1b) e "Só sei como fizemos desta vez. Fomos ao delegado de saúde e polícia..." (F1b).

\section{DISCUSSÃO DOS RESULTADOS}

Os extractos de algumas entrevistas são disso exemplo: "custa-me vê-lo assim e não poder fazer nada (...) eu não sei o que hei-de fazer" (B1). "isto já se arrasta há dois anos e não consigo médico que consiga descobrir o problema dele (C1). Aparentemente a situação que Ihes traria mais tranquilidade seria a de prolongar o tempo de internamento "era bom que ele estivesse cá muito tempo a ver se fica completamente curado, mas isso depende (...) depende do doutor, não é? ..."(A1) ou "A minha mulher quer que ele esteja aqui meio ano. Mas eles com certeza também não querem que ele esteja aí meio ano. Às tantas querem despacha-lo" (A2).

Adaptar-se à uma situação de doença mental não é fácil. Nas famílias que entrevistamos podemosidentificar um sentimento de insegurança e desconforto diante da imprevisibilidade do seu comportamento futuro e apesar de aguardarem alguma expectativa positiva convivem com o medo de que algo súbito possa acontecer: "a mudança de humor (...) ele em cinco minutos consegue ficar super agressivo e esse é o problema maior (B2). "É inseguro ter uma pessoa daquelas em casa porque não se pode estar 5 minutos descansados (...) tem de haver sempre uma pessoa que o acompanhe 24 horas por dia ou senão não estamos descansados" (C1).

A integração no meio é relativamente fácil de se conseguir quando se conhece os espaços e como nos movemos neles. Com comportamentos imprevisíveis pode tornarse embaraçoso ou incapacitante esta adaptação social. Para ajudar a ultrapassar esta dificuldade a família deve ter ao seu dispor alguma informação sobre os possíveis comportamentos que o doente pode apresentar face a uma situação de descompensação.

As famílias revelam não saber o que fazer porque não sabem nada sobre a doença ou sobre como lidar com o seu familiar e notamos a diferença que elas próprias sentem sobre a explicação que lhes é dada se enfrentam um problema orgânico ou um problema psíquico. O filho de $\mathrm{C}$ faz um paralelismo interessante sobre a informação que recebeu 
ao ser-Ihe diagnosticada uma doença orgânica e respectivos cuidados e a informação recebida relativamente à doença do pai: "No caso da minha doença, chamaram-me a mim, à minha esposa e à minha mãe e explicaram como devia lidar com a situação em casa, os cuidados que devia ter, o que devia ou não fazer, explicaram tudo ao pormenor", conta "aqui a única informação que nos deram foi em caso de acontecer..., chamar a ambulância (...) e evitar as coisas ao alcance dele. O que é complicado porque é uma pessoa que toma dez comprimidos por dia" (C 1).

Um aspecto que pode ser entendido como um certo "pôr à margem" os familiares, (pelos profissionais de saúde) é o facto de encontrarmos com relativa frequência expressões que denotam não terem conhecimento do estado e do evoluir da doença, como: "Não. Nunca fui informada de nada. Não sei" (A1). E continua: "Eu... o que sei é que quando ele é agressivo eu deixo e muitas vezes fecho-me no quarto (...) ou fecho-me na casa (...) onde eu estou, estou fechada! daí por um bocado saio outra vez e já está melhor" (A1). "Só na net...e a psiquiatra falou comigo mas...é assim dá-me a ideia que eles também não sabem como lidar" (B1). Aparentemente este comportamento agressivo do doente poderia ser controlado ou minorado com pequenas interacções na relação entre mãe e filho se houvesse alguém do exterior que mediasse a interacção.

Outras situações encontradas que não se coadunam com viver com qualidade de vida são as dificuldades em manter relacionamentos afectivos com os outros, incluindo os que Ihe estão próximo e perdas de competência social, embora algumas vezes o tentem ocultar justificando o afastamento como: "Eu acho que eles têm vergonha (...) do filho ter um problema" (B1). "Enquanto familia nunca tivemos, do resto da família, grande apoio (...) a partir do momento que surgiu o problema..." (C2); "escondem, abafam (...) na minha família tentam abafar" (C3); ou "... se me perguntarem digo que está na praia" (A1).

Os recursos que se podem utilizar para lidar com a situação desagradável podem ser internos ou externos mas passam sempre pela aquisição de algumas competências que se vão adquirindo com a própria convivência. Podem passar por aprender a lidar com a doença e com as suas implicações, deixando muitas vezes projectos por realizar. "eu ter os meus objectivos, eu trabalhar e lutar por ter uma vida melhor e ter ao meu lado uma pessoa que é completamente diferente de mim (...) é complicado (...) é muito complicado" (B1). Estar com estes doentes em casa é uma permanente carga emocional e que facilmente nos é transmitida: "eu já percebi que a doença não tem cura (...) o internamento é um descanso" (B2), ou: "eu não sei como lidar com ele" (C3). Ao longo dos anos, com a tomada de consciência que a doença mental não tem cura leva a um sentimento de exaustão "sinto-me frustrada porque (...) sei que ele vai criar outra vez expectativas como quando saiu da outra vez e não vai acontecer nada e depois vai outra vez abaixo (...) vai acontecer exactamente a mesma coisa; portanto daqui a um ano se calhar nem isso vai estar aqui outra vez (...) perceba a minha impotência." (B1). Alguns elementos referem ser importante a ajuda divina, através da oração: "Peço todos os dias a Deus" (A1).

Os apoios que as famílias encontram quando o seu familiar descompensa, no final da primeira década do século XXI, são o recurso às forças policiais. Com falta de serviços de acompanhamento destas famílias a única forma de encontram quando o elemento doente entra numa nova crise o primeiro recurso é a GNR (Guarda Nacional Republicana). "Fui à guarda (leia-se: GNR)" ... delegação de saúde e o delegado... de um dia pró outro tratou dos papéis, e trouxe-o p'r' aqui" (B1).

Depois de várias décadas a estudar-se as repercussões que a doença mental traz para as famílias, como demonstram os estudos Marsh (1992), podemos concluir que continua a ser necessário insistir na necessidade de incluir a família em todo o processo do cuidar.

Os familiares estão envolvidos com o doente e, por isso, as estratégias de intervenção terapêutica terão que contemplar todos os elementos do agregado que sintam essa necessidade para que se restabeleça o equilíbrio. Assim tornar-se-á mais fácil que a família adopte comportamentos e padrões de interacção familiar compatíveis com a gestão da ansiedade que o impacto da doença causa, melhora a capacidade de envolvimento nos novos papéis e funções da família, a qualidade das relações com o doente e ajustam novas atitudes em relação à doença, se for necessário.

Sabemos que nem sempre é fácil identificar-se correctamente a causa da doença mental. Sabemos, inclusive, que a maior parte das vezes há um emaranhado de causas, ligadas entre si que torna complexo atribuir qual dela tem mais influencia na desadaptação do individuo ao meio onde está inserido. No entanto, pensamos que os conhecimentos actuais permitem oferecer uma informação à família que a ajude a aceitar as alterações de comportamento do seu familiar, causadas pela doença que, por sua vez, serão facilitadoras das relações interfamiliares.

As políticas de saúde actuais vão no sentido de se manterem os doentes na comunidade, mas isso só será possível se a família estiver preparada para lidar com eles e com as implicações da doença mental. A "... culpa, a sobrecarga, o pessimismo e o isolamento social..." (Souza e Scatena, 2005: 174) são manifestações comuns a todas as famílias do nosso estudo, tal como o isolamento social e conflitos interpessoais na família.

Tivemos oportunidade de observar que os familiares se deslocam aos serviços de internamento em vários momentos, essencialmente nas seguintes situações: visitar o doente, falar com o médico para que este colha informações sobre o doente ou quando o doente vai passar um fim-de-semana a casa. Em todos os momentos as intervenções são centradas no doente. Se questionam sobre a evolução do estado de 
saúde do seu familiar as respostas mais frequentes são: "está bem", "está melhor". As famílias ao dirigirem-se aos técnicos aguardam mais que isto. Estes momentos podem ser reservados, também, para um diálogo centrado na família. Uma correcta intervenção junto das famílias, esclarecendo sobre os sintomas e reforço sobre a necessidade de adesão à terapêutica são importantes, mas as possibilidade de sucesso são mais elevadas se forem acompanhadas de estrategias para lidar com o familiar doente,como evitar os conflitos a críticas desvalorativas ao doente bem como um encaminhamento correcto se observarem alguma alteração do comportamento ou se se prevê uma situação geradora de maior ansiedade que possa implicar alguma mudança nos cuidados ao doente. Algumas vezes, acredito, que se as familias tivessem a abertura por parte dos enfermeiros ou dos médicos do serviço de lhes poderem telefonar numa situação geradora de stress, a sobrecarga emocional diminuiria consideravelmente. São pequenas intervenções que podem ser uteis pois permitem ao familiar não se sentir só e sabe a quem recorrer em momentos de crise e fariam a diferença em todo o processo terapeutico.

Está-se a cuidar a familia quando esta é ajudada a compreender os comportamentos do doente, quando Ihe é reconhecido o esforço para cuidar do seu familiar, ora vigiando comportamentos, ora colaborando para a adesão terapeutica, mas, e essencialmente, escutandoos e valorizando as suas dificuldades, centrando-as nos problemas actuais auxiliando-a a negociar soluções ou adoptar novas formas para lidar com os problemas.

\section{CONCLUSÕES}

Face a uma análise que ainda não é exaustiva, devido à fase de desenvolvimento do estudo, já podemos, no entanto, extrair algumas conclusões.

Assim, algumas famílias têm dificuldade em se adaptar à situação de doença mental num dos seus membros, vivendo permanentemente em situação de angustia e medo, chegando a manifestarem esgotamento.

Têm dificuldade em se organizarem face à ocorrência de doença. Muitas vezes nem aceitam que haja doença o que dificulta a procura de estratégias eficazes para lidarem com a situação. Frequentemente preferem isolar-se dos grupos sociais, inclusive da família alargada para tentarem esconder o estigma que ainda permanece na comunidade. Esta realidade é bem documentada na expressão: "é daquele tipo de doenças invisiveis que á partida, se fosse uma perna partida ou uma dor qualquer... não....é aquela dor silenciosa que as pessoas custam um bocado... eu próprio apesar de já acompanhar isto á oito anos, foi-me difícil de entender" (F15c).

A conclusão que se torna mais pertinente reter refere-se à atitude dos enfermeiros perante o sofrimento destas famílias.
Não encontramos referências claras a apoio que estes profissionais oferecem.

$\mathrm{Na}$ fase em que se encontra o estudo ainda não nos atrevemos a apontar soluções no sentido de ajudar as famílias a desenvolver estratégias saudáveis para que sejam capazes de ultrapassar as dificuldades causadas pela doença mental. Acreditamos que teremos oportunidade de concluir este objectivo num futuro próximo e partilha-lo com todos os que lidam com estas famílias.

Devemos lembrar que se o objectivo da promoção da saúde familiar é recuperar a saúde de todos os membros da família, quando, por qualquer razão esta está ameaçada (Stanhope e Lancaster, 1999), pelos dados que já possuímos podemos afirmar que ainda há muito a fazer para ajudar as famílias dos doentes mentais.

Não nos devemos esquecer que quem cuida é o enfermeiro e este deve ter "cada vez mais clara a percepção das capacidades, das qualificações e das competencias que desenvolvem quotidianamente" não podendo nem devendo ter "dificuldade em assumir um papel mais significativo na construção e desenvolvimento da saude das pessoas, grupos e sociedade" (Amendoeira, 2006:24).

\section{REFERÊNCIAS BIBLIOGRÁFICAS}

Amendoeira, J. (2006). Enfermagem, disciplina do conhecimento. In: Sinais Vitais, n. ${ }^{\circ} 67$, Julho, 19-27.

Amaral e Durman, (2004). O que pensa a família sobre o atendimento oferecido pela Psiquiatria. Disponivel em: http:// periodicos.uem.br/ojs/index.php/ActaSciHealthSci/ articlevi ewFile/1629/1064.

Alarcão, M. (2000). (des)Equilíbrios familiares. Coimbra, Quarteto.

Bomar, J. P. (1996). Nurses and family health Promotion: Concepts, assessment, and interventions. Philadelphia: W.B. Saunders.

Comissão das Comunidades Europeias (2005). Livro verde - Melhorar a saúde mental da população: rumo a uma estratégia de saúde mental para a União Europeia.

Comité Económico e Social Europeu (2006). Parecer sobre o Livro verde - Melhorar a saúde mental da população: rumo a uma estratégia de saúde mental para a União Europeia.

Colvero,L. A.; Ide, C.A.C.; e Rolim, A. A. (2004). Família e doença mental: a difícil convivência com a diferença. In: Rev Esc Enferm, USP38(2), 197-205.

Fawcett, J. (2000). Analysis and evaluation of contemporary 
nursing knowledge: nursing models and theories. Philadelphia: F. A. Davis Company.

Fernandes, A. (1995). Métodos e regras para elaboração de trabalhos académicos e científicos. Porto Editora: Porto.

Gubman, G. D.; Tessler, R. C. (1987). The impact of mental illness on families. In: journal of Family Issues, vol. 8, $n^{\circ} 2$, , p. 226-245.

Marsh, D.T.; Johnson, D.J. (1997). The family Experience of mental illness: implications for intervention. In: Professional Psychology: research and practice, vol. 28, $n^{\circ} 3,229-237$.

Marsh, D.T. (1992). Families and Mental Illness: New directions in professional practice. New York: Praeger.

Martins, M. M. F. P. S. (2002). Uma crise acidental na família: o doente com AVC. Formasau: Coimbra.

Martins, M. S. M. (2003). A família, um suporte ao cuidar. In: sinais Vitais, $n .^{\circ}$ 50, 52-56.

McCubbin, M.A. (1993). Family stress theory and the development of nursing knowledge about family adaptation. In S.L. Feetham; S.B. Meister; J.M.Bell; e C.L. Gillis - The Nursing Family. New Bury Park: Sage Publications, 46-58.

McCubbin, M. A., e McCubbin, H.I. (1989). Families coping with illness: The resiliency model of family stress, adjustment and adaptation. In: Danielson C. B.; Hamel-Bissel B.; e P.Winstead-Fry - Families, health e illness: Perspectives on coping and intervention. St. Louis: Mosby.

Minuchin, S. (1990). Famílias: Funcionamento e Tratamento. Porto Alegre: Artes Médicas.

Minuchin, S; Fishman, H. Ch. (1989). Técnicas de terapia familiar. Barcelona: Ediciones Paidos.

Nasi, C.; Stumm, L. K.; Hildebrant, L. M. - Convivendo com o doente mental psicótico na ótica do familiar. Revista Electrónica de Enfermagem, v. 06, n. 01, 2004. Disponível em www.fen.ufg.br
Oliveira, R.M.P.; Loyola, C.M. (2004) - Família do paciente psiquiátrico: o retrato de uma ilustre desconhecida. Acta Scientiarum. Health Sciences, vol. 26, n.1, p. 213-222.

OMS (2002). Relatório mundial de saúde 2001: nova compreensão, nova esperança. Ministério da Saúde. Lisboa: Direcção-Geral da Saúde.

Olson, D. H. [et al.] - (1989) - Families. Los Angeles: Sage.

PNSM (2008). Disponivel em: http://www.acs.min-saude.pt

Quivy, R. e Campenhoudt, L. V. (1994). Manual de Investigação em Ciências Sociais. Lisboa: Edições Gradiva.

Scazufca, M.(2000). Abordagem familiar em Esquizofrenia. In: Rev Bras Psiquiatr: 22 (Supl I), 50-52.

Souza, R.; Scatena, M. C. M.(2005) - Produção de sentidos acerca da família que convive com o doente mental. Rev Latino-am Enfermagem; Março Abril; 13(2):173-9. Disponivel em: www.eerp.usp.br/rlae.

Schene, A. H.; Tessler, R.C.; e Gamache, G.M. (1994). Instruments measuring family or caregiver in severe mental illness. Social Psychiatry Epidemiological.

Stanhope, M. (1999). Teorias e Desenvolvimento Familiar. In Stanhope, M. \& Lancaster, J. Enfermagem Comunitária: Promoção de Saúde de Grupos, Famílias e Indivíduos. 1. ${ }^{a}$ ed. Lisboa : Lusociência, pp. 492-514.

Relvas, A. P.; Alarcão, M. (2002). Novas formas de famílias. Coimbra: Quarteto.

Vaz Serra, A. Stress (1994). Coimbra: Coimbra Médica.

Wright, L. M.; Leahey, M. (2000). Enfermeiras e famílias, um guia para avaliação e intervenção na família ( $3^{a}$. ed.). São Paulo: ROCA.

www.saude-mental.net/index.2009.04.07 